\title{
Special Education-An Education Programme Still in Input
}

\author{
Gaolin Cai ${ }^{1, \dagger}$, Zhijian Wei ${ }^{2, *}{ }^{*}$, Yike Wong ${ }^{3, \dagger}$ \\ ${ }^{1}$ Vanke Meisha Academy, Shenzhen, Guangdong, China \\ ${ }^{2}$ Kang Chiao International School, East China Campus, China \\ ${ }^{3}$ Hangzhou Entel Foreign Language School, Hangzhou, Zhejiang, China \\ *Corresponding Email:09163@kcisec.com \\ ${ }^{\dagger}$ These authors contributed equally.
}

\begin{abstract}
Overall, there are have many problems about special education Nowadays. Although It's still in dispute, we can't ignore its advantages and disadvantages. Its intended to be very suitable for problem children, it get good results in certain areas. Moreover, its core mechanism is very well because special children really need a learning program suitable for them and the special education is trying to achieve this. But today's special education is still difficult to be fully implemented, whether in terms of parents, teachers or interpersonal communication, Special education is still flawed. It seems like many people are still skeptical about the plan. Many scholars are still making efforts in this area , Society generally attaches great importance to the education of children. After understanding a lot of academic research and scientific theories, it is still difficult for us to have a comprehensive, complete, quantitative and qualitative consideration of it, but We thinks that after further social practice and experiment, the scheme may be more comprehensive and perfect.
\end{abstract}

Keywords: Special Education, Inclusion Education, Children with disabilities

\section{INTRODUCTION}

From supporters of social Darwinism in the 19th century regarding child with special needs as the "unfit" that would disturb natural selection from choosing the "fittest" characteristics for human offspring, to President Gerald Ford signing the Education for All Handicapped Children Act (EAHCA) in the late $20^{\text {th }}$ century with the very first Individualized Education Program (IEP) introduced into school system, children with special needs are being perceived more rightfully along with the advancement of educational psychology and rising awareness of individual differences [1].Thus, governments and educators are building policies and adjustment in response to the rising concern of meeting the educational needs of child with special needs. Since children with special needs are expected to learn as efficiently as "normal" children, children with special needs tend to struggle more academically in school [2]. The disability these children suffer varies in four major types which are physical, developmental, behavioral or emotional, and sensory impaired. Moreover, children with special needs also tend to struggle emotionally since they too often fail to succeed academically [2]. Tragically, general educators are either not prepared enough to deal with children with special needs [3] or not educated enough to be empathetic toward the children's condition [4]. Moreover, placing children with special needs in ordinary schools can also be problematic.

Disadvantages, the population of disabled children, children with mental issue, and student with learning disabilities have increase significantly. Arguments about what education system is the best fit to allocate this population in have been discussed for a long period of time. Whether we should segregate them into special education system or assign them into the normal school system is the subject that had been debated and argued the most. On the perspective of exclusion propose, people suggest that if we exclude the student with various disabilities from the normal group of students, then they would take up more probability to lose the chance to participate with social activities or economic activities. Reason of this issue are because of the segregation of disabled children would diminish the social contact with others [5]. Several educators suggest 
that exposing children with disabilities into general education system would help students with disabilities construct self-confidence and equipping children into better self-supportive adults in the future [6]. However, many educators state that including the disabled children in the normal education system would create harm to them. Educators find out that segregation education system is benefit the students with disabilities due to help them find appropriate curriculum and help them study with people who like them. It helps students with disabilities gain self-esteem and enhance their confidence [6]. Also, when students with disabilities tend to have more problematic social behavior and not been accept well by their classmates in the ordinary school system [7].

Therefore, exactly what will happen if a problem child learning in the special education? There are some pros and cons found. First, he is getting individualized help [8]. Also, There are many positives to draw from when your child is going into special education classes. Relief knowing that they are getting the specialized education they need, smaller class sizes which result in more one-on-one attention, specialized approaches to teaching that are more conducive to those that have struggled with mainstream education, students with special needs often find they excel at specific subjects - observe your child's interests and talents, and being assessed and classified is better than not if your child is genuinely struggling and showing signs they require a different approach [9]. Second, Special education students are kept taking away from their classmates in many subjects and taught in separate classrooms with other special education students. This segregation can be emotionally and intellectually damaging. For these reasons, many schools try to keep their special education and general education students together, but this generally results in the special education student failing behind, as they need more support. To combat this, many schools include special education teachers in the general classroom to assist the general education teacher with their special education students[10].

It looks like there are many advantages but in fact, it still have many malpractice. Sometimes terminology used within the realm of special education can come with negative connotations. One of these terms, "classified", can be particularly off-putting, and cause parents of potential special education students to feel uneasy about going forth and accepting services. With the word "classified" comes associations that include labeling and even stigma[9]. Second, Typically the teacher's extra helper. In this instance, "Co-planning is important, however in my experience there is no extra time. If an instructional aide goes in the classroom without training, the student typically learns 'learned helplessness," meaning the child grows accustomed to having assistance and is less likely to attempt independent work [8].
The impact of special education is complex and multifaceted. Based on the abovementioned literature, although more research has emerged recently on special education, the current research is still messy and limited. The impact of special education is still not clear and comprehensive, so the purpose of this article is to systematically and clearly analyze and summarize the impact of special education by reviewing elevant articles and research in recent decades.

\section{INCLUSION EDUCATION}

People today can be approximately separate into two big proportions. Either propose to segregate children with special needs or disabilities, and implement a segregation learning system, or like people who advocate that we should arrange the children with special needs or various kinds of disabilities within the ordinary school system. With the second circumstance, educators define it with the term "Inclusion Education."

Inclusion Education is considered as one of the most effective way to get all children either handicaps or normal to engage in schools. When handicaps children been placed in education system, they have opportunity to gain knowledge, develop skills, and socializing with kids that are normal, because they are placed in the same classroom with the normal children. It diminishes the chances of the disabled children been abandon by the society in the future [11]. Educators and parent have different opinions toward the inclusion education system.

\section{BENEFITS OF INCLUSION EDUCATION SYSTEM}

Educators, parents, and governments found that segregate children with special needs into isolate education system is discriminatory and highly unfair. Due to the mature education system, ordinary school system obtains the ability to help all children include children with special needs to meet their requirement and needs. Moreover, teachers in the segregation education systems seem to be less comprehensive, and their teaching ability and range seem to be limited. If children with disabilities and various needs are exposure within the ordinary school system, they are more likely to engage with different learning style and more comprehensive knowledge. Study in the ordinary school system, help all the children to standout with their own characteristic, and it help emphasizes kids' growth and needs[12]. Ordinary school can full-fill all the necessities and requirements that can help a children grow and study, so it is unnecessary for government or organizations to establish segregation education system.

Segregation education system in some cases have been documented morally incorrect by some educators. 


\section{CHILDREN WITH DISABILITIES HAVE THE RIGHTS TO RECEIVE EDUCATIONAL RESOURCES}

Isolating children with disabilities or with special needs from sharing educational resources with normal children in ordinary school system is discriminative. People being argue that children with special needs or disables would create various kinds of disturbance and chaos in class by sudden roar or create violent toward staffs and classmates [13]. Furthermore, children with disabilities or with special needs have usually been documented as problematic and have the higher percentage to become the victim of bully. Due to the poor social acceptance, children with disabilities somehow are viewed as the social deficit, and it create less chances for them to alternating with normal children while they are existing in an environment which the majority of them are normal children. The probability for children with disabilities or with special needs are less likely to have a good engagement and well performance in the society after they grow up[14]. Besides these, inclusion education system sometime are being wrong defined. People sometime ignore the type of disabilities the children have, such as deaf, blind, or dumb. These are the type of disabilities that would create hard time for teacher to look after them. It will be unfair for normal students because children with disabilities or with special needs have taken away too much time and mind from teachers, which are also a kind of huge consumption of educational resources [14]. However, the original intention of inclusion education was good. The solution to these contradictions is to create excellent educational resources, for examples, providing training to teachers to help them rational allocate their time and mind on children with special needs, and give considerably time to teach other students to accept children with disabilities and curb students' bully actions over students with disabilities. One of the crucial goals that inclusion education system tries to achieve is to help disabled children to generate leadership and better social skills [15]. Social skills development can be taken place while group projects, speech, and actively engage in class discussion, which means that a higher probability of successful career that disable students can achieve in the future[12].

\section{SPECIAL EDUCATION}

Special education students are sometimes separated from the rest of the class, which can be isolating, so it may affect some children to adapt to society. Rebecca's daughter Claire (now 20, the second of four children) received a designation as "gifted" through their local school board when she was 9 years old. According to Rebecca, here's what it meant:
Access to a congregated regional program from grades 4-8 that put her in a classroom with other gifted children. "The program was creative and engaging, staffed by motivated and specialized teachers. It reengaged her in learning. And, as it was embedded regular school, it also exposed her to stigma and teasing. By Grade 7, she was tired of being labelled 'Giftie' and of being with the same group of 20 students every day. She started doing everything she could to be accepted by the mainstream students, and it led to some poor social choices on her part."

Access to the Special Education resources at her high school, which "in practice meant that she had someone willing to rearrange her timetable to give her excellent teachers." More information for us as her parents. "Her test results and subsequent designation prompted us to research giftedness more so that we could understand better how her brain works."

After high school? Rebecca says Claire's gifted classification "has meant virtually nothing."[16]

\section{DOWN SIDE OF SPECIAL EDUCATION}

Special education cannot give comprehensive education sometimes. An internationally recognized expert in the field of education, who will remain anonymous, recently (2019) said, "I gave up on special education a long time ago, praying that no child/grandchild of mine would ever need an IEP." After 45 years of advocacy and four children, two of whom had an IEP, I concur. In discussions at conferences and workshops, I have found that the most knowledgeable among us are the most discouraged. It is like knowing the cure and not being able to use it to save the sick.

-"The amount of course work in the structure of spoken and written language required by teacher preparation programs and state certification standards is woefully inadequate for the demands of classroom life, particularly classrooms with low-readiness children and a diverse range of learners" [17].

-"Most teachers are not being given the content and depth of training needed to enable them to provide appropriate instruction" [17].

•"Teachers need ongoing professional development that has topical continuity, practical application, and opportunities for collaboration with peers" [17].

•"'Properly certified' teachers are often 'improperly prepared' to deliver effective instruction" [17].

These quotes go back more than twenty years; with the exception of rare pockets of excellence, the situation has not improved[17]. 


\section{SPEICAL EDUCATION'S EFFECTS PSYCHOLOGICAL DEVELOPMENT}

Special education may affect students' psychological development. Sometimes terminology used within the realm of special education can come with negative connotations. One of these terms, "classified," can be particularly off-putting, and cause parents of potential special education students to feel uneasy about going forth and accepting services. With the word "classified" comes associations that include labeling and even stigma.[9].

\section{HARMS TO ACADEMIC EDUCATION}

Harm to students with disabilities' academic education: Parents fear that general education teachers do not have the training and skills to accommodate special needs students in a general education classroom setting. However, professional training and supportive services can usually address these concerns. Some research has suggested teachers who are not aware ofand later may choose not to adopt-modifications needed for students with special needs are also more resistant to having these students in class. This can lead to regression of the students with disabilities as well as overall decreased classroom productivity[18].

\section{SPECIAL EDUCATION'S ADVANTAGES}

Special always means individual. Most "problem children" can get more suitable education. In any classroom, there often are significant learning gaps between individuals. The challenge is to assist struggling students while simultaneously engaging gifted learners, but that is exactly what individualized instruction aims to do: delivering material at an optimal pace that caters to each student's interests and abilities. Persistence in difficult topic areas while moving at a 'just right' pace through areas in which the student excels is the way to close learning gaps and bring everyone to their highest personal level of achievement[19].

Special education can prevent students from influencing each other. When the special kids learning in a common class, they may slow down the course and make classroom education low. On the other hand, problems students are often bullied. Which means special education can protect these students sometimes.

\section{POSSIBLE SUGGESSTION}

\subsection{Inclusion Education}

It is obvious that disabled children could have many opportunities to socialize with normal children, and some school is capable enough of keep disabled children in regular classes; however, many problems are still concerning parents and schools.

\subsubsection{Teacher's resistance to accommodate needs of disabled children}

Some teachers in inclusion education are resistant to adjust the class in order to meet particular needs of disabled children and this could be a very serious problem affecting children's learning journal. Nonetheless, disabled children's parents need to be wary about the class their children enrolled in. It is recommended that parents keep close communication with school and children to ensure that teachers are treating their children rightfully with adequate adjustment to support the children.

\subsubsection{Disturbance caused by disabled children during class}

Some disabled children do struggle to stay focused and quiet during class and it distracts a class and slow down the pace of teaching. Parents of this type of children do need to be very aware of the symptoms and seek for sufficient support from clinical psychologist. Besides, efficient communication between school and parents must be built for parents to keep up with their children's development and progress of their treatment progress.

\subsubsection{Bully and Social Rejection}

Disabled children are more likely to be bullied and not socially accepted due to their unusual characteristics. It is indeed not very realistic to require every normal child to be educated and tolerant enough to not bully disabled children; therefore, parents must be aware of the risk of their children being bullied or socially excluded. Moreover, parents must be considerate of children's feeling and ensure that the communication between them are mutual and respectful in order to ensure that the children are feeling secure enough to reveal their feelings and tell these incidents in time when they do encounter these serious problems in school.

\subsubsection{Large consumption of education resources}

One last concern so far is the large consumption of education resources from disabled children which seems unfair to normal children. It should not be a very big problem in school because although it is undeniable that disabled children demand more teacher's time and energy than normal children; nonetheless, the proportion of disabled children is not high enough to exhaust a regular school. To reduce the chance of having too many disabled children in one class and overworking 
any particular teacher, school should simply distribute disabled children to its classes evenly. As long as a teacher has enough time and energy to support every child in their classes, it should be acceptable that disabled children taking more education resource than normal children.

\subsection{Exclusion Education}

Although exclusion education aims directly at meeting the needs of disabled children, it must not be regarded as no-brainer to send a disabled children to exclusion education. although exclusion education aims directly at meeting the needs of disabled children, it must not be regarded as no-brainer to send a disabled children to exclusion education.

\subsubsection{Social Isolation}

Social isolation seems inevitable in exclusion education since it's one of the essential parts of exclusion education. However, despite disabled children being kept away from regular students during school, the parents still can take time to expose their children to the world outside of inclusion education. Assisting disabled children to socialize with regular children can help them better adapt to real life, and indeed it could be extraordinarily difficult for both the parents and children at the very first attempt, but the discomfort is only a matter of time. It is better to go through the struggle of socialization when parents are there to help rather than leaving the children to face the struggle alone in the future when parents may not be able to offer support timely.

\subsubsection{Inadequate Teacher And Program}

The exclusion education for disabled children often fails to provide programs that can meet the demand of the parents, and many teachers are not prepared enough to assist the disabled. children. For parents, what they can do for their children is to be very selective about the program or institution they are applying. Given the current circumstance, evaluating the quality of the education and teacher becomes crucially important for parents to ensure that the education is properly designed to meet the particular disability of their children.

\subsection{Label And Stigma}

Parents are concerned about disabled children being labeled and stigmatized, but it is undeniable that their children are different than the regular children. They can only help their children when they know what is special about them and make some adjustments for that. Moreover, regarding the concern of stigma, schools should promote more about disabled children to teach students and parents not to hold discrimination and stigma against disabled children. And for parents or disabled children feeling afraid of being the stigma, seeking out for help or educate yourself could be a good option.

\section{CONCLUSION}

Despite the fact that special education is particularly designed for children with special needs, inclusion education still seems to be a good choice for parents and students. It's not that inclusion education has many advantages over exclusion, but because exclusion education has many problems. Indeed, children with special needs are considered problematic and disturbing, but they still could develop comprehensive skills from inclusion education. And teachers in ordinary school are fairly competent enough to teach these children despite some of them being reluctant to adjust for the children with special needs.

On the other hand, exclusion education too often lacks competent teachers that are trained and prepared enough to interact with the children which defeats the purpose of sending the children to these programs. And this problem is not new, it's been decades and many institutions still fail to solve it. Regardless of that, many other challenges are concerning the parents as well. Issues such as social isolation away from normal children and stigmatization are prevailing within exclusion education. In addition, some people are against it simply because they believe it is discriminating to treat the children differently.

Nonetheless, education is never solely the responsibility of schools, there are many things people as a parent can do. Whether they choose inclusion or exclusion education, they all need to be careful about the program they are applying to and they all need to build an effective communication with their children to consistently follow their latest performance at school. And whether students are marked as troublesome in inclusion education or struggling with social isolation or any problems during school or elsewhere, parents need to respond to these issues in time to reduce the negative impact as much as possible.

\section{REFERENCES}

[1] N. Hobbs, (1975, May 31). The futures of children: Categories, labels and their consequences. (highlights, summary, and recommendations for The final report of the project on classification of Exceptional Children). ERIC. Retrieved October 2, 2021, from https://eric.ed.gov/?id=ED115069.

[2] P., N. (n.d.). Adjustment problems faced by children with learning disabilities- impact of special education. Journal of Education and Practice. Retrieved October 2, 2021, from 
https://iiste.org/Journals/index.php/JEP/article/vie w/10797.

[3] M. L. Barton, (1991, November 30). Teachers' opinions on the implementation and effects of mainstreaming. ERIC. Retrieved October 2, 2021, from https://eric.ed.gov/?id=ED350802.

[4] D. Horne, J. L. R. Marcia(n.d.). Hierarchy of response to handicaps - Marcia D. Horne, Jerry L. Ricciardo, 1988. SAGE Journals. Retrieved October 2, 2021, from https://journals.sagepub.com/doi/10.2466/pr0.1988. 62.1.83.

[5] The Open University. Social History of Learning. Disability. (n.d.). Retrieved October 2, 2021, from https://www.open.ac.uk/health-and-socialcare/research/shld/resources-andpublications/publications

[6] J. C. Jenkinson (n.d.). Mainstream or special?: Educating students with disabilities. Google Books. Retrieved October 2, 2021, from https://books.google.com/books/about/Mainstream _Or_Special.html?id=z9OROHm0nSoC.

[7] Peer Group membership and. (n.d.). Retrieved October 2, 2021, from https://www.jstor.org/stable/pdfplus/1002108.pdf.

[8] Dyslexia services / dyslexia services. /. (n.d.). Retrieved October 2, 2021, from https://www.dallasisd.org/Page/74987.

[9] E. N. Celletti, (2019, March 19). Pros and cons of your child being classified as a special education student. Niche. Retrieved October 2, 2021, from https://www.niche.com/blog/pros-and-cons-ofyour-child-being-classified-as-a-special-educationstudent/.

[10] Van Brocklen. Russell, - Chief research officer teaching ... (n.d.). Retrieved October 2, 2021, from https://www.linkedin.com/in/russell-van-brocklen$2007 \mathrm{ab} 87$.

[11] Inclusive education. UNICEF. (n.d.). Retrieved October 2, 2021, from https://www.unicef.org/education/inclusiveeducation.

[12] H. L. Wang. (2009, November). Should all students with special educational needs (SEN) be included in mainstream education provision? Retrieved October 2, 2021, from https://files.eric.ed.gov/fulltext/EJ1065757.pdf.

[13] mld5644. (2017, March 1). Controversies in education. Retrieved October 2, 2021, from https://sites.psu.edu/civicissueedu/2017/03/01/sepa rate-classrooms-for-disabled-students/.

[14] D. M. Murphy. (1996, May 1). Implications of inclusion for general and special education: The Elementary School Journal: Vol 96, no 5. Retrieved October 2, 2021, from https://www.journals.uchicago.edu/doi/abs/10.1086 1461840.

[15] Inclusive Education and its benefits. New Brunswick Association For Community Living (NBACL). (n.d.). Retrieved October 2, 2021, from https://nbacl.nb.ca/module-pages/inclusiveeducation-and-its-benefits/.

[16] Sutherns. Rebecca, PhD CPF - CEO - sage solutions | linkedin. (n.d.). Retrieved October 2, 2021, from https://ca.linkedin.com/in/rebeccasutherns.

[17] Why is special education a failure? International Dyslexia Association. (2020, February 26). Retrieved October 2, 2021, from https://dyslexiaida.org/why-is-special-education-afailure/.

[18] C. Glavin, (2018, September 27). Mainstreaming disadvantages in special education. Mainstreaming Disadvantages in Special Education | K12 Academics. Retrieved October 2, 2021, from https://www.k12academics.com/educationsubjects/specialeducation/mainstreaming/disadvantages.

[19] N. Green (2015, August 6). Pros and cons of individualized instruction. DreamBox Learning. Retrieved October 2, 2021, from https://www.dreambox.com/blog/pros-consindividualized-instruction 